\title{
Coupling Biorational Tactics with Radio-Genetic F1 Sterility Technique for an Effective Integrated Pest Management against Lepidopteran Insects
}

\section{Seth RK*, Vimal N, Sengupta M, Angmo N, Dhal M K and Seth R Department of Zoology, Applied Entomology and Radiation Biology Unit, India}

*Corresponding author: Rakesh Kumar Seth, Department of Zoology, Applied Entomology and Radiation Biology Unit, Delhi- 110 007, India, Email: rkseth57@gmail.com

\section{Mini Review \\ Volume 1 Issue 4}

Received Date: August 17, 2018

Published Date: September 17, 2018

\begin{abstract}
Insect pests belonging to Lepidopteran order species are amongst the most damaging pests of food and fiber crops globally. Lepidopteran pests are often managed imprudently by spraying crops with large amounts of broad-spectrum and often persistent insecticides. In view of the increased occurrence of insecticidal resistance, and their negative impacts on the environment and ecosystems, the need for biorational environment friendly control tactics and eco-compatible Integrated Pest Management (IPM) strategy is becoming imperative and crucial. Both the sterile insect technique (SIT), and its refinement, Inherited (F1) Sterility (IS) technique offer a great potential as additional control tactics for integration with other control methods in area-wide IPM approaches against the lepidopteran pests. SIT/IS can only be applied successfully when the released sterile insects effectively compete with their wild counterparts for mating with wild females. There are a number of programmes where the SIT/IS has been used efficiently against key lepidopteran pests, and there is a great potential for further improvement and expansion of the SIT/IS technology to target other economically important lepidopteran pests. Sterile insect programmes (SIT/IS) as a parabiological control may be compatible with other biorational methods of control (viz., mating disruption, use of parasitoids, pathogens and predators, biorational molecules such as hormone mimics/agonists/antagonists, inhibitors for sperm activity, pheromone blockers, metabolic inhibitors, physiological disruptors, etc.) that may fetch enhanced or synergistic potential towards area-wide IPM against the lepidopteran pests, provided the employment of different biorational tactics is well orchestrated with their mode of action and targeted ontogenic stage of the pests.
\end{abstract}

Keywords: Biorational; F1 sterility technique; Biopesticides; Parabiological control; IPM

Abbreviations: IPM: Integrated Pest Management; SIT: Sterile Insect Technique; AW-IPM: Area-Wide
Concept of Integrated Pest Management; IS: Inherited Sterility; EPNs: Entomopathogenic Nematodes; IGR: 


\section{International Journal of Zoology and Animal Biology}

Insect Growth Regulators; SNPs: Silica Nanoparticles; IAEA: International Atomic Energy Agency.

\section{Introduction}

Earlier (mid twentieth century) the insect pest control was mostly based on broad-spectrum conventional insecticides such as organochlorines, organophosphates, carbamates and pyrethroid; however, the severe adverse effects of pesticides on the environment and human health, problems of crucial insecticidal resistance and stricter regulations and legislation resulted in reducing their use. Hence, to use ecologically sound alternatives and novel methods for pest control that may constitute 'biorational' approaches are the vital tasks in pest control for the twenty-first century.

The term 'biorational' (biological + rational) approach can be defined as the use of specific and selective strategy having biological perspective as the main basis. The biorational strategy may include biologically based technique, or chemicals that may mimic/antagonize the biomolecules, often with a unique mode of action, and that are compatible with natural enemies and the environment, with minimal effect on non-target organisms. Biorational pest control is based on an interactive mode of diversity of chemical, biological and physical approaches for controlling insect pests which results in minimum risk to human and the concerned environment.

The economic thresholds and economic injury levels due to serious insect pests, realized within an ecological framework where chemical and biological controls could thrive together is probably the basis for the Integrated Pest Management (IPM) concept. However, during the last six decades, IPM's overdependence on various broadspectrum insecticides led to a reproach that IPM was merely an integrated pesticide management [1]. Many countries are switching over from chemical based agriculture to green agriculture, where utilization of biorational methods (biopesticides, biological and parabiological control methods) have a great role to play [2-4].

Lepidopteran pest species are among the most damaging species of food and fibre crops around the world $[5,6]$, especially designated as the worst insect pest threats faced by the tropical countries. These pests cause severe losses to agricultural crops in vast areas all over the world, and are the target of very significant quantities of broad-spectrum and persistent insecticides in developed and developing countries. These interventions are unsustainable in view of the economic impact of these pests. The rapid development of insecticide resistance in some Lepidopteran pests presents an additional threat to sustainability [7,8]. Furthermore, many effective pesticides are being removed from the market due to increased recognition of long-term human health and environmental harm caused by their wide-spread use.

Using sterile insect technique (SIT) is an environmentfriendly control method that includes the use of sterile insects to control insects of the same species [9]. Another consideration in favour of mounting area-wide interventions using SIT against moth pests is the increasing commercial pressure to reduce residues on food. The use of SIT becomes more attractive compared to other alternatives if costs can be decreased. Further, the global increase in trade and travel has resulted in an increase in the rate of invasion of lepidopteran species, which threaten agricultural systems, markets, communities and biodiversity on a worldwide basis. In the current scenario, various tools of physiology, toxicology, and biotechnology can help us realize the role and potential of biorational strategies to be coupled with sterile insect programmes in an efficacious IPM module for the suppression of lepidopteran pests.

\section{Area-Wide Integrated Pest Management for Lepidopteran Pests}

\section{Sterile Insect Technique (SIT)}

There is a broad international conceptual thinking that pest control operations against the lepidopteran pests should be based on the area-wide concept of integrated pest management (AW-IPM), and that SIT can be considered as a key tactic for creating pest free areas or for pest management within IPM programmes. It has been known since the 1950's that insect pests can be controlled or eradicated through a "birth control" method based on genetic manipulation, known as autocidal pest control, or the sterile insect technique (SIT). It involves the colonization and mass-rearing of the target pest species, sterilization of the insects through the use of gamma radiation, and their release into the field on a sustained basis and in sufficient numbers to achieve appropriate sterile to wild insect over-flooding ratios. The sterile insects need to find and mate with fertile, virgin insects, rendering the wild population infertile. Due to the nonappearance of offspring, the natural pest population will suppress. The validity of this method has been demonstrated for many insect pests, including many moths, screwworms, tsetse, and fruit flies [10]. 
The sterile insect technique is recognized among the first biological control methods designed for area-wide integrated pest management programs (AW-IPM) which integrate various control tactics against a pest population within a delimited geographical area. Other tactics include pesticide applications to reduce the size of initial populations and mating disruption or non-commercial wild host plant management to reduce the immigration of wild pest populations. Various strategies can be exercised when using SIT in AW-IPM, viz., pest eradication, suppression, containment or prevention [11]. Although SIT is considered an environmentally friendly method, undesired effects may occur; the pre-release population suppression is often based on insecticide applications that can be harmful to the environment, and SIT targeting native species can threaten biodiversity, although the direct and indirect effects of SIT on the environment are addressed by Nagel et al. [12] for both native and exotic pests.

\section{Modified SIT as F1 Sterility Technique - A Favorable Alternative to Manage Lepidopteran Pests}

Lepidopteran species are more resistant than other insect species against radiation; thereby a much higher dose of radiation is required to achieve sterility which may in turn reduce the insects' competitiveness in the field against wild variety [13]. One way to overcome this drawback of SIT is to use 'Inherited Sterility' or F1 sterility by releasing sub sterile male moths [14-17]. Therefore, a refinement of the SIT for Lepidoptera, known as 'Inherited Sterility' (IS), also known as 'F1 sterility' technique involves lowering the irradiation dose that moths receive (which would result in nearly completely sterile female moths and partially sterile male moths with almost fully sterile offspring) and consequently increasing their competitive fitness. Moths treated with a lower sterilizing dose live longer, are stronger fliers, and show better mating competitiveness than the moths treated with higher radiation doses. When inherited sterility systems are implemented into moth SIT programs, great improvements in programme efficiency can be obtained.

The use of SIT/IS as a control tactic has many advantages, including species specificity and compatibility with the use of other area-wide control tactics such as mating disruption, biological control, cultural control methods and the use of bio-rational pesticides. It is an environmentally-friendly technology that can be used to address many of the world's most difficult pest control problems. There are many successful examples of SIT against Lepidoptera. These include operational containment, suppression and eradication programmes against the codling moth (Canada) [18], pink boll worm (USA) [19], cactus moth, Cactoblastis cactorum (USA) [20], painted apple moth, Teia anartoides (New Zealand) [21], and false codling moth Thaumatotibia leucotreta (South Africa) [22,23]. In addition, there have been trial projects to demonstrate feasibility in the field; e.g. gypsy moth Lymantra dispar (L.), tobacco budworm Heliothes virescens (F.), corn earworm, oriental fruit moth, carob moth Ectomyelois ceratoniae, Asian corn borer Ostrinia furnacolis, the common cutworm Spodoptera litura, the spotted pod borer Maruca vitrata, etc [24,25].

\section{Integrating SIT/ F1 Sterility and Biological Control}

Use of SIT programmes is not expected to conflict with other bio-control methods, such as mating disruption [26], augmentation of entomopathogens [27], host-plant resistance [28,29] and natural enemies [30].

\section{Parasitoids}

The release of radio-sterilized or sub-sterile insects together with biological control agents has been known to have positive or sometimes synergistic effects for population suppression when applied simultaneously [31-33]. This synergy results from the sterile insects targeting on the adult stage, while the biological control agents usually target the immature stages wherein the reproduction of these bio-control agents on the F1 offspring produced in the inherited sterility releases would further supplement the strategy. Laboratory and field trials with the cotton bollworm Helioverpa armigera, the corn earworm $H$. zea (Boddie), L. dispar, the potato tuber moth Phthorimaea operculella (Zeller), the diamondback moth Plutella xylostella, the tropical armyworm, Spodoptera litura (Fabr.), and the beet armyworm $S$. exigua (Hubner) indicated that sterile progeny from semi-sterile moths were acceptable as hosts for egg and larval parasitoids [34-38].

Experiments under large laboratory cage conditions showed that F1 sterility and releases of Trichogramma principium (Sugonyaev \& Sorokina) were effective in suppressing $P$. operculella. Properly timed releases of $T$. principium together with moths irradiated at $250 \mathrm{~Gy}$ produced the greatest reduction in $P$. operculella F3 progeny, demonstrating the synergistic effects of combining F1 sterility with egg parasitoids [35]. Investigations on interaction and compatibility of two biorational pest control tactics, (i) Trichogramma chilonis as bioconrol agent and (ii) radio-genetic 'F1 sterility 


\section{International Journal of Zoology and Animal Biology}

technique', against Spodoptera litura indicated that inundative releases of $T$. chilonis (egg parasitoid) with F1 sterility technique could be efficacious using 100Gy and 130Gy as sub-sterilizing doses in F1 sterility technique, whereas inoculative releases of parasitoid might be efficiently operated using only $100 \mathrm{~Gy}$ in the radio-genetic pest suppression method [39].

Eggs of the false codling moth Thaumatotibia (Chryptophlebia) leucotreta (Meyrick) treated with 150200Gy were acceptable and suitable for development of the egg parasitoid Trichogrammatoidea cryptophlebiae Nagaraja. Field-cage evaluations in citrus orchards in South Africa revealed that releases of irradiated (150 and 200 Gy) moths combined with releases of $T$. cryptophlebiae provided enhanced suppression of the false codling moth populations [40]. Integrating augmentative releases of Diglyphus isaea (Walker) as a parasitoid of a vegetable pest celery miner fly Liriomyza bryoniae (Kaltenbach), with sterile males of L. bryoniae was proposed for application in greenhouses $[41,42]$.

Mass releases of the olive fruit fly parasitoid $P$. concolor, reared on irradiated Mediterranean fruit fly larvae, were coupled with mass trapping for an environmental friendly suppression method of olive fly populations [43].

\section{Predators}

The interaction of the predator, Tupiocoris cucurbitaceous (Hemiptera: Miridae) was studied with biorational 'Inherited sterility' technique being employed against a serious pest Tuta absoluta. The predator, Tupiocoris cucurbitaceous fed on the F1 sterile eggs (produced by sub-sterilized males crossed with unirradiated females) significantly more than on normal eggs [44].

In South America, the exotic predator on weed Opuntia sp. is Cactoblastis cactorum, which being an exotic insect has gained the status of pest by devastating native plant species. F1 sterility technique was used for controlling Cactoblastis cactorum. The F1 larvae of sub sterilized $C$. cactorum was also observed to add to the predator's feed while concurrently controlling the pest population by producing sterile progeny [45]. Therefore, the F1 sterile insects not only controlled the insect population on their own, but also acted as fodder for the predators in the field to help flourish their population while simultaneously acting synergistically together towards pest suppression. This additive effect of both the techniques can be achieved by simultaneous or consecutive incessant release of F1 progeny with the natural predators.

\section{Pathogens}

The usage of various species of entomopathogenic nematodes (EPNs) was complementary with F1 sterility technique against the pink bollworm, Pectinophora gossypiella, and the success of using both the techniques was dependent upon the foraging behavior of the nematode. The F1 larvae became more susceptible to nematodes as the radiation dosage in the male parent was increased. Further, the suitable EPN species (i.e., Steinernema carpocapsae) was used, and these nematodes were more likely to infect normal mobile larvae than the F1 sedentary larvae [46], that might contribute towards effective pest suppression.

Efficacy of the entomopathogenic nematode (EPN), Steinernema glaseri, (Steiner) cultured in radio-sterilized host, was studied in relation to radiation-mediated F1 sterility technique on a tropical lepidopteran pest, Spodoptera litura (Fabr) $S$ glaseri, harvested from F1 sterile larval hosts (progeny from 100 or 130 Gy treated male parents) retained a reasonably high degree of infectivity on normal and F1 sterile $S$. litura hosts (61$83 \%$ of controls). Two promising operational modes of integrating $S$. glaseri EPNs with 'F1 sterility' to suppress $S$. litura populations (initial releases of EPNs to strongly suppress the pest density followed by use of F1 sterility versus simultaneous use of both techniques) were proposed for effective pest management [36].

The painted apple moth, Teia anartoides Walker (Lepidoptera: Lymantriidae), is an Australian plant defoliator, and an important pest in horticulture and forestry. An IPM program was implemented by integrating sequential applications of Foray 48 (Bacillus thuringiensis) along with release of sterile males and F1 and $\mathrm{F} 2$ radio-sterile progenies, which resulted ultimately in official eradication of the pest from that area within two years [21].

\section{Integrating SIT/ F1 Sterility and Pheromones}

Insects have a highly specialized and sensitive pheromone olfactory system, which is crucial to their survival. The lepidopterans use pheromones as sex attractants as an integral part of their mate-finding strategy. Using SIT/IS programmes is not expected to negatively encounter with other eco-sound control 


\section{International Journal of Zoology and Animal Biology}

methods, such as mating disruption using pheromones [26].

One of the appropriate methods is mating disruption using synthetic pheromones either implemented alone [47] or integrated with cultural practices [48], 'attract and kill' [49-52]. In 1992, an operational codling moth AWIPM programme (OKSIR programme - OkanaganKootenay Sterile Insect Release Programme) released the sterile males in the Okanagan region of British Columbia, Canada to apple and pear orchards [53]. The programme integrated the use of insecticidal sprays, mating disruption and tree banding with the release of sterile moths [54], and the results of this programme were encouraging. There are various ways in which the pheromones and insect hormones can be utilized to manipulate the insect population under economic threshold. Pheromone traps can be used to capture the male moths by using female pheromones as baits. The codling moth, Cydia pomonella was kept under control by using pheromone traps using codlem one as bait [21]. Moreover, the bioassays to assess the responses of released irradiated males to the pheromone traps were indispensable to any SIT/F1 sterility programmes and crucial for monitoring irradiated moths throughout the target area $[11,55]$.

Light brown apple moth, Epiphyas postvittana is a leafroller invading Australia, Europe and North America. An IPM program was developed to combine SIT with mating disruption strategy in 2007 [56]. A population model was developed in support of implementing the integration of mating disruption technique with Inherited Sterility (IS) instead of SIT for light brown apple moth $[57,58]$. The model concluded that IS at higher doses leads to almost complete eradication of pest population while at lower doses, there is a chance of formation of a self-sustaining population and thus combination of IS with other tactics is necessary.

The SIT or F1 sterility programmes can only be successful when sterile moths of high biological quality are released [59]. Behavioral traits, such as dispersal, response to calling females, flight propensity and ability of the released male moths largely influence the success of the SIT in the field [59,60]. SIT in conjunction with other insect controls such as mating disruption could further reduce the frequency of insecticide use and residual concern [61]. SIT can be effectively implemented alongside other IPM methods including mating disruption and threshold-based pheromone trap sprays, etc.

\section{Prospective Biomolecules as Biorational Pesticides to Couple with SIT/F1 Sterility Programmes}

\section{Plant Derived Products}

Plant terpenes such as limonoids from Meliaceae plants, flavonoids from Asteraceae, sesquiterpenes from Celastraceae, etc, are usually a good source of compounds for pest management, since they are eco-friendly and offer strong resistance to insect attack. The activity of some of these compounds has been associated with a mechanism involving inhibition of AChE. Ent-clerodanes from the aerial parts of Gutierrezia microcephala (Asteraceae) and b-dihydroagarofurans, isolated from Maytenus sp., exhibited insecticidal activity inhibiting growth, pupation and emergence on larvae of Spodoptera frugiperda [62]. The latter compounds were potent inhibitors of AChE (78-100\% inhibition at $15 \mathrm{ppm})$ with the most potent toxic agent on adults [63]. Similar results were reported with insecticidal triterpenes isolated from Parthenium argentatum [64]. The most efficient natural substance with moult-inhibiting activity is azadirachtin, a tetranortriterpenoid plant (neem tree, Meliaceae) limonoid with ecdysteroid-like structure [65]. Its strong antifeedant, insect growth regulatory and reproductive effects are well documented, although its biochemical effects at the cellular level are still uncertain. Brassinosteroids represent the first true antiecdysteroids investigated. They are a family of growthpromoting hormones found in plants and have striking structural similarities with the ecdysteroids. The brassinosteroids compete with moulting hormones at the binding site of the hormone receptor which results in delayed moulting [66]. Two triterpenoids isolated from seeds of a cruciferous plant, cucurbitacins B and D, were found to be insect steroid hormone antagonists acting at the ecdysteroid receptor [67].

\section{Biomolecules Acting as Mimics/Agonists/Antagonists to Hormones, Neuropetides and Pheromones}

In the search for safer biorational pest control molecules, i.e., more selective modes of action and reduced risks for non-target organisms and the environment, a considerable progress has been made with the development of natural and synthetic compounds capable of interfering with the processes of growth, development and metamorphosis of the target insects [68]. These chemicals are called insect growth regulators (IGR) or third-generation insecticides [69,70]. IGRs exert their insecticidal effects through their 


\section{International Journal of Zoology and Animal Biology}

influence on development, metamorphosis and reproduction of the target insects by disrupting the normal activity of the endocrine system, although their action is considerably slower than that of the synthetic chemical insecticides. Hence, the insect endocrine system can be considered as a potential and specific physiological target for pest control. New bio-rational approaches to the development of insect control agents have been revealed through the description of natural and synthetic compounds capable of interfering with the processes of development and reproduction of the target insects. These novel biorational insecticides that mimic the action of major insect growth and developmental hormone classes-the neurohormones (neuropeptides), the ecdysteroids and the juvenile hormones, could be systematically integrated with SIT/F1 sterility for efficacious lepidopteran pest control. Any interference in the homeostasis of these hormones with exogenous source of the hormones or with synthetic analogs (agonist or antagonist) would result in the disruption or abnormal course of development and reproduction of the target insect. Many processes in the insects are regulated by peptides originating from various parts of the nervous system. These processes include stimulation of moulting by initiating ecdysteroid biosynthesis, initiation of behavioral patterns associated with ecdysis and its timing, control of JH biosynthesis, water and ion balance, influence of contractions of visceral muscles and regulation of energy metabolism. A significant progress has been made in the characterization of these neuropeptides and their genes [71]. In addition to the peptides themselves, the mechanisms responsible for their synthesis, maturation, transport, secretion, binding, action, and inactivation offer several targets for the development of novel biorational insecticides.

In insects, the prothoracic glands are the major source of ecdysteroids during larval development. The involvement of alternative sites of ecdysteroid production (ovary, testes, and abdominal integument) is limited to pupal and adult stages. Ecdysteroids are synthesized from cholesterol or phytosteroids in the diet, because the insects cannot synthesize the steroid nucleus. The final steps of ecdysone biosynthesis consist of a sequence of hydroxylations catalyzed by cytochrome P-450dependent hydroxylases. Several P-450 inhibitors could be promising bio-pesticides. Ketokonazole, another synthetic imidazole derivative, is known to inhibit the ecdysone 20-monooxygenase and was effective against adult locusts and crickets [72,73]. Such biorational molecules at lethal and sublethal concentartions need to be tested against the lepidopteran pests.
The discovery of ecdysteroid agonists (RH-5849, RH5992-tebufenozide, RH-2485) has been very effective [74]. These molecules are ecdysteroid agonists belonging to bisacylhydrazine class, and act against a wide range of lepidopteran pests. All these non-steroidal ecdysone agonists manifest their effects via interaction with the EcR/USP receptor complex. The high degree of safety with respect to non-target organisms is particularly remarkable. Use of sublethal sterilizing doses of bisacylhydrazine ecdysone agonist insecticides (RH-5849 and RH-5992-tebufenozide) interfered with male reproductive ability and showed the potential to adversely affect the population dynamics of S. litura, and to achieve population suppression of this serious pest [75].

Certain highly active compounds with less apparent similarity to $\mathrm{JH}$ (aromatic non-terpenoidal JH analogs) like fenoxycarb, pyriproxifen and diofenolan, have been synthesized [76]. Different formulations of fenoxycarb have been used for the control of a number of lepidopteran pests. The juvenoids have some merits, like their short residual effects in the field and the few and short sensitive phases of the target insects [77]. However, since juvenoids act only on certain stages their application must be timed precisely, and due to their low field stability, it needs to be repeated several times. Hence, JH analogs are the most practical where immediate control is not desired. Several potential inhibitors of JH biosynthesis, viz., fluoromevalonate, mevinolin and fluvastatin have been investigated [78]. An inhibitor of JH biosynthesis, isolated from the entomopathogenic fungus Penicillium brevicompactum, was observed to inhibit the final methylation/epoxidation steps of $\mathrm{JH}$ hormone biosynthesis [79].

Another tactic can be to produce pheromone and hormone antagonists. Many crucial genes and subsequent peptides like PBAN (pheromone biosynthesis activating neuropeptides), leucokinins, juvenile hormones have been identified which play a role in pheromone and hormone synthesis, and development of their inhibitors will positively help in pest management strategies [21]. Once detected by antennae, the pheromone is degraded by pheromone-degrading enzymes, which include monooxygenases, aldehyde oxidases, aldehyde dehydrogenases, esterases and glutathione-Stransferases. Use of inhibitors of the catabolism of the odorant molecules, as disruptants of pheromone reception, has been proposed as a potential approach for insect control [80]. Peptides released by specialized 


\section{International Journal of Zoology and Animal Biology}

neurosecretory cells of the insect's central nervous system (neuropeptides) may function as neurotransmitters, neuromodulators and as hormones and have been called the 'master regulators' of development, behavior, metabolism, homeostasis and reproduction. Several novel insect neuropeptides and numerous peptide analogs have been synthesized, a large number of gene sequences have been determined and neuropeptides genes have been expressed in vector systems. It is impractical to consider neuropeptides themselves as pest control agents since their physicochemical properties would render them susceptible to degradation under field conditions and to be digested after feeding and their polarity would make their uptake through the cuticle most difficult. But it is worth considering neuropeptides as potential leads to control agents, as their structural information included within the molecules, might provide clues to the manner in which the active neuropeptides could be synthesized, and processed to act upon a target tissue, and degraded [81]. The disruption of any step leading to biosynthesis of neuropeptides, their modification during storage, and their release into the hemolymph as well as their interaction with the target cell membrane-bound receptors may offer multiple modes of action for a novel neuropeptides based insect control strategy (fourth generation insecticides).

\section{Biomolecules Disrupting Sperm Activation}

Lepidoptera males have concomitantly nucleate (eupyrene) and anucleate (apyrene) spermatozoa. Both kinds of spermatozoa reach the spermatheca of inseminated females but only the eupyrene ones have the capacity to fertilize the eggs [82]. The functions of the apyrene spermatozoa are still uncertain. Physiologically, the highly motile apyrene sperm seem to act as micro stirring bars to facilitate the dissociation of eupyrene sperm bundles in spermatophores after copulation [83]. Eupyrene spermatogenesis is regular and highly sensitive to genetic and experimental manipulations while apyrene spermatogenesis is irregular and withstands these manipulations. Both kinds of spermatozoa are derived from the same kind of bipotential spermatocytes. After copulation, both sperm types migrate to the spermatheca, where the eupyrene sperm are stored until oviposition by the female. Many studies report that apyrene sperm represent the majority of sperm stored in the spermatheca [84-86]. Silberglied, et al. [87] proposed the cheap filler hypothesis, which states that, in polyandrous species; the numerous motile apyrene sperm in the spermatheca reduce the receptivity of the female to remating. Activation of sperm motility involves structural and metabolic changes of the spermatozoa, or it involves chemical stimuli, which may lead to the initiation of motility. In the male silkworm, Bombyx mori L. (Lepidoptera: Bombycidae), the secretions of the glandula prostatica, which contain an Endopeptidase called initiator in, trigger a cascade of reactions in the apyrene sperm $[88,89]$. Sperm motility probably results from selective degradation of the glycoprotein by an Arg-C Endopeptidase, and then deposition of cAMP on the surface of the cell membrane or in the microslits [90]. Therefore, use of inhibitors for sperm motility in Lepidopteran insects might be a potential biorational mode of intercepting sperm dynamics and eventual reproductive disruption leading to pest suppression.

\section{Phenoloxidase Inhibitors}

Phenoloxidase (PO), the enzyme responsible for the biosynthesis of melanin, is considered as an important component of insects' immune system. The enzyme is not only involved in defense reactions but also in other physiologically important processes, such as sclerotization of the cuticle, an essential step for the survival of all insects [91]. Use of phenoloxidase inhibitors could act as a potent biorational insecticide targeting the various pre-imaginal stages undergoing metamorphosis in lepidopteran pest.

\section{Bio-Nanoparticles}

Nanoparticles in agriculture may serve as 'magic bullets', containing insecticides, fungicides, herbicides, chemicals, or genes, which can target particular plant parts or organisms to release their content. Nanocapsules can enable effective penetration of pesticides through cuticles and tissues, allowing slow and constant release of the active substances [92]. Nano-particles as biopesticides usually exhibit extra ordinary strength, more chemical reactivity and possess high electrical conductivity. Biological nanomaterials have a substantial role in new pesticidal designs. For instance, Silica nanoparticles (SNPs) could effectively kill early instars of Spodoptera litura [93]. Chandrashekharaiah, et al. [94] developed DNA-tagged nanogold, DNA-tagged CdS, nano-TiO2 and nano-Ag that showed a significant mortality of the immature stages of $S$. litura.

\section{Biorational Mode}

Most of the noxious chemical pesticides/biomolecules are either neuro-poisons or physiological disruptors, and a majority of these pesticides have anti-reproductive effects at sub-lethal doses that need to be exploited in IPM, before employing their lethal doses, which would (i) allow using lower doses of deadly chemicals, (ii) slow 
down the rate of development of insecticidal resistance in insect pest, that would in turn lead to an ecologically sound approach for pest suppression.

\section{Conclusion}

The control of lepidopteran pests worldwide is achieved almost entirely through the use of synthetic insecticides. This dependence on insecticides has contributed to the development of insecticide resistance in many of the most serious pests. Development of alternative tactics to the unilateral use of insecticides is a major emphasis of most local, national and international research organizations concerned with lepidopteran pest control. Radio-genetic Inherited Sterility (IS), also referred to as F1 sterility, would be an appropriate alternative to suppress Lepidopteran pest population, wherein radiation induced deleterious effects can be inherited and well expressed in the F1 generation. Keeping in mind the complexity of farming systems world-wide and pressure to maintain environmental integrity, radio-genetic Inherited Sterility, which cannot be considered a stand-alone technology, must be integrated with ecologically compatible biorational control tactics (using biocontrol agents and biopesticides)in a biorational mode for an effective pest suppression under appropriate IPM module (Figure 1).

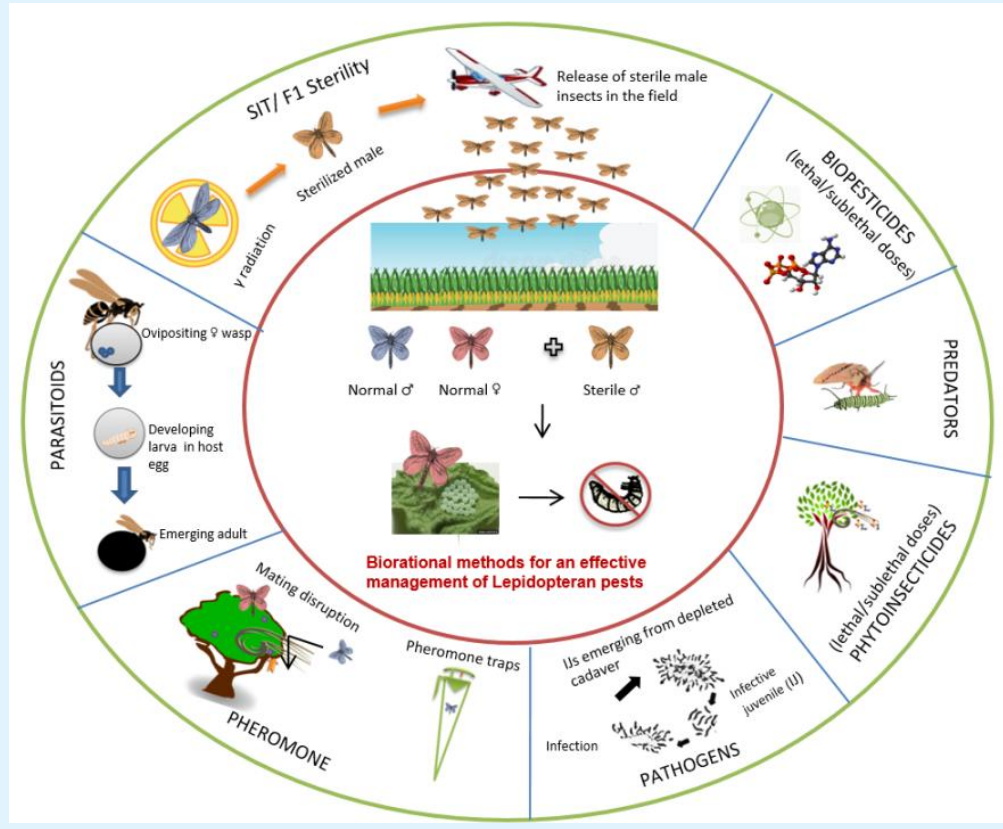

Figure 1: Biorational tactics (Biological control + Biopesticides) complementing SIT/F1 sterility programmes for an effective IPM against Lepidopteran insects.

\section{Acknowledgement}

The author (RKS) is grateful to the International Atomic Energy Agency (IAEA) and Ministry of Agriculture, Govt. of India for supporting the long term research work on using nuclear technology in Lepidopteran pest control.

\section{References}

1. Ehler LE (2006) Integrated pest management (IPM): definition, historical development and implementation, and the other IPM. Pest management science, 62(9): 787-789.

2. Stadler T, Buteler M, Weaver DK (2010) Novel use of nanostructured alumina as an insecticide. Pest Manag Sci 66(6): 577-579.

3. Watson GB, Loso MR, Babcock JM, Hasler JM, Letherer TJ (2011) Novel nicotinic action of the sulfoximine insecticide sulfoxaflor. Insect Biochem Mol Biol 41(7): 432-439. 


\section{International Journal of Zoology and Animal Biology}

4. Gogos A, Knauer K, Bucheli TD (2012) Nanomaterials in plant protection and fertilization: current state, foreseen applications, and research priorities. J Agric Food Chem 60(39): 9781-9792.

5. Peters T M (1987) Negative insect-human interactions. Insects and Human Society. AVI Book, Van Nostrand Reinhold Co., New York, pp: 223-292.

6. ESA (Entomological Society of America) (2001) Selected worst pest threats to US agriculture and plant resources. Unpublished report prepared by the Entomological Society of America for the U.S. Department of Agriculture, Animal and Plant Health Inspection Service.

7. Varela LG, Welter SC, Jones VP, Brunner JF, Riedl H (1993) Monitoring and characterization of insecticide resistance Codling moth (Lepidoptera: Tortricidae) in four Western States. Journal of Economic Entomology 86(1): 1-10.

8. Tabashnik B E (1994) Evolution of resistance to Bacillus thuringiensis. Annual review of entomology, 39(1): 47-79.

9. LaChance L E (1985) Genetic methods for the control of lepidopteran species. USDA Agricultural Research Service 28: 1-40.

10. Vreysen MJ, Klassen W, Carpenter JE (2016) Overview of technological advances toward greater efficiency and efficacy in sterile insect-inherited sterility programs against moth pests. Florida Entomologist 99(1): 1-12.

11. Vreysen MJ, Hendrichs J, Enkerlin WR (2006) The sterile insect technique as a component of sustainable area-wide integrated pest management of selected horticultural insect pests. J Fruit Ornam Plant Res 14(3): 107-131.

12. Nagel P, Peveling R (2005) Environment and the sterile insect technique. Sterile Insect Technique, Springer, Dordrecht pp: 499-524.

13. Suckling DM, Charles J, Allan D, Chhagan A, Barrington A, et al. (2005) Performance of irradiated Teia anartoides (Lepidoptera: Lymantriidae) in urban Auckland, New Zealand. J Econ Entomol 98(5): 15311538.

14. Proverbs MD, Newton JR (1962) Influence of gamma radiation on the development and fertility of the codling moth, Carpocapsa pomonella (L) (Lepidoptera: Olethreutidae). Canadian Journal of Zoology, 40(3): 401-420.

15. Knipling EF (1970) Suppression of pest Lepidoptera by releasing partially sterile males: a theoretical appraisal. Bioscience 20(8): 465-470.

16. Knipling EF (1979) The basic principles of insect population suppression and management. The basic principles of insect population suppression and management, pp: 512.

17. Carpenter JE, Bloem S, Marec F (2005) Inherited sterility in insects. Sterile Insect Technique, Springer, Dordrecht pp: 115-146.

18. Bloem KA, Bloem S, Carpenter JE (2005) Impact of moth suppression/eradication programmes using the sterile insect technique or inherited sterility. Sterile Insect Technique, Springer, Dordrecht pp: 677-700.

19. Henneberry $\mathrm{T} J(2007)$ Integrated systems for control of the pink bollworm Pectinophora gossypiella in cotton. Area-Wide Control of Insect Pests, Springer, Dordrecht, pp: 567-579.

20. Carpenter JE, Hight SD, Bello A (2008) Eradication and containment of Cactoblastis cactorum in Mexico and the United States. XXIII International Congress of Entomology, Durban, South Africa, pp: 6-12.

21. Suckling DM, Barrington AM, Chhagan A, Stephens AEA, Burnip GM, et al. (2007) Eradication of the Australian painted apple moth Teia anartoides in New Zealand: trapping, inherited sterility, and male competitiveness. In Area-wide control of insect pests, Springer, Dordrecht, pp: 603-615.

22. Hofmeyr JH, Carpenter JE, Bloem S, Slabbert JP, Hofmeyr M, et al. (2015) Development of the sterile insect technique to suppress false codling moth Thaumatotibia leucotreta (Lepidoptera: Tortricidae) in citrus fruit: research to implementation (Part 1). African Entomology 23(1): 180-186.

23. Hofmeyr JH, Hofmeyr M, Carpenter JE, Bloem S, Slabbert JP (2016) Sterile insect releases for control of Thaumatotibia leucotreta (Lepidoptera: Tortricidae): an assessment on semi-commercial scale. African Entomology 24(1): 80-89.

24. Eyidozehi K, Fanooj MAH, Mokhtari A (2015) The sterile insect technique and inherited sterility in 


\section{International Journal of Zoology and Animal Biology}

lepidoptera. Biological Forum-An International Journal 7(1): 1871-1874.

25. Patil BV, Seth RK (2017) Final report on Joint ProjectInvestigations on the present pigeonpea pest complex and their management with emphasis on radiation technology as an integral component in IPM. Min of Agriculture, Govt of India pp: 165.

26. Bloem S, Carpenter JE (2001) Evaluation of population suppression by irradiated Lepidoptera and their progeny. The Florida Entomologist 84(2): 165-171.

27. Hamm JJ, Carpenter JE (1997) Compatibility of nuclear polyhedrosis viruses and inherited sterility for control of corn earworm and fall armyworm (Lepidoptera: Noctuidae). Journal of Entomological Science 32(2): 148-153.

28. Carpenter JE, Wiseman BR (1992a) Effects of inherited sterility and insect resistant dent-corn silks on Helicoverpa zea (Lepidoptera: Noctuidae) development. Journal of Entomological Science 27(4): 413-420.

29. Carpenter JE, Wiseman BR (1992b) Spodoptera frugiperda (Lepidoptera: Noctuidae) development and damage potential as affected by inherited sterility and host plant resistance. Environmental entomology 21(1): 57-60.

30. Greany PD, Carpenter JE (1999) Use of nuclear techniques in biological control of insects and weeds. Nuclear news 42: 32-34.

31. Knipling EF (1992) Principles of insect parasitism analyzed from new perspectives. Practical implications for regulating insect populations by biological means. U.S Department of Agriculture. Agriculture Handbook No. 693, 349pp.

32. Wong TT, Ramadan MM, Herr JC, McInnis DO (1992) Suppression of a Mediterranean fruit fly (Diptera: Tephritidae) population with concurrent parasitoid and sterile fly releases in Kula, Maui, Hawaii. Journal of Economic Entomology 85(5): 1671-1681.

33. Bloem S, Bloem KA, Knight AL (1998) Oviposition by sterile codling moths, Cydia pomonella (Lepidoptera: Tortricidae) and control of wild populations with combined releases of sterile moths and egg parasitoids. Journal of the Entomological Society of British Columbia 95: 99-110.
34. Novotny J, Zubrik M (2003) Sterile Insect Technique as a Tool for Increasing the Efficacy of Gypsy Moth Biocontrol. General Technical Report pp: 80-86.

35. Saour G (2009) Effect of early oviposition experience on host acceptance in Trichogramma (Hymenoptera: Trichogrammatidae) and application of $F_{1}$ sterility and T. principium to suppress the potato tuber moth (Lepidoptera: Gelechiidae). Biocontrol Science and Technology 19(1): 225-234.

36. Seth RK, Barik TK, Chauhan S (2009) Interaction of entomopathogenic nematodes, Steinernema glaseri (Rhabditida: Steinernematidae), cultured in irradiated hosts, with 'F1 sterility': Towards management of a tropical pest, Spodoptera litura (Fabr.) (Lepidoptera: Noctuidae). Biocontrol Science and Technology 19(1): 139-155.

37. Wang E, Lu, Liu X, Li Y (2009) Evaluating the use of nuclear techniques for colonization and production of Trichogramma chilonis in combination with releasing irradiated moths for control of cotton bollworm, Helicoverpa armigera. Biocontrol Science and Technology 19(1): 235-242.

38. Zubrik M, Novotny J (2009) Impact of gamma radiation on the developmental characteristics of the gypsy moth, Lymantria dispar (Lepidoptera: Lymantriidae) preparatory to their use as supplemental hosts/prey for natural enemy enhancement. Biocontrol Science and Technology 19(1): 291-301.

39. Dhal MK (2013) Assessment of compatibility of egg parasitoid Trichogramma chilonis Ishii with irradiation induced F1 Sterility technique towards management of noctuid pest, Spodoptera litura (Fabricius). Ph.D. thesis. University of Delhi

40. Carpenter JE, Bloem S, Hofmeyr JH (2004) Acceptability and suitability of eggs of false codling moth (Lepidoptera: Tortricidae) from irradiated parents to parasitism by Trichogrammatoidea cryptophlebiae (Hymenoptera: Trichogrammatidae). Biological Control 30(2): 351-359.

41. Kaspi R, Parrella MP (2008) Synergistic interaction between parasitoids and sterile insects. IOBC WPRS BULLETIN 32: 99-102.

42. Steinberg S, Cayol JP (2009) Synergism between biological control and sterile insect technique: Can commercial mass production of biocontrol agents and 


\section{International Journal of Zoology and Animal Biology}

sterile insects be integrated within the same industrial entity? Biocontrol Science and Technology 19(1): 271-275.

43. Hepdurgun B, Turanli T, Zümreoğlu A (2009) Control of the olive fruit fly, Bactrocera oleae, (Diptera: Tephritidae) through mass trapping and mass releases of the parasitoid Psyttalia concolor (Hymenoptera: Braconidae) reared on irradiated Mediterranean fruit fly. Biocontrol Science and Technology 19: 211-224.

44. Cagnotti CL, Andorno AV, Hernández CM, Paladino LC, Botto EN, et al. (2016) Inherited sterility in Tuta absoluta (Lepidoptera: Gelechiidae): Pest population suppression and potential for combined use with a generalist predator. Florida Entomologist 99(1): 8794.

45. Carpenter JE, Bloem KA, Bloem S (2001) Applications of F1 sterility for research and management of Cactoblastis cactorum (Lepidoptera: Pyralidae). Florida Entomologist 84(4): 531-536.

46. Gouge DH, Smith KA, Lee LL, Henneberry TJ (1998) Control of pink bollworm Pectinophora gossypiella (Saunders)(Lepidoptera: Gelechiidae) with entomopathogenic nematodes (Rhabditida: Steinernematidae) and gossyplure in cotton. Recent research developments in entomology pp: 55-85.

47. Moffitt HR, Westigard PH (1984) Suppression of the codling moth (Lepidoptera: Tortricidae) population on pears in southern Oregon through mating disruption with sex pheromone. Journal of Economic Entomology 77(6): 1513-1519.

48. Judd GJR, Gardiner MGT, Thomson DR (1997) Control of codling moth in organically-managed apple orchards by combining pheromone-mediated mating disruption, post-harvest fruit removal and tree banding. Entomologia Experimentalis et Applicata 83(2): 137-146.

49. Trematerra P, Fontana F, Mancini M, Sciarretta A (1999) Influence of intact and damaged cereal kernels on the behaviour of rice weevil, Sitophilus oryzae (L.) (Coleoptera: Curculionidae). Journal of Stored Products Research, 35(3): 265-276.

50. Charmillot PJ, Hofer D, Pasquier D (2000) Attract and kill: a new method for control of the codling moth Cydia pomonella. Entomologia Experimentalis et Applicata 94(2): 211-216.
51. Kovaleski A, Mumford J (2007) Pulling out the evil by the root: the codling moth Cydia pomonella eradication programme in Brazil. Area-wide control of insect pests, Springer, Dordrecht: 581-590.

52. Mansour R, Grissa Lebdi K, La Torre I, Zappalà L, Russo A (2009) Preliminary study on mealybugs in two vineyards of the Cap-Bon Region (Tunisia). Tunis J Plant Prot 4(2): 185-196.

53. Dyck VA, Graham SH, Bloem KA (1993) Implementation of the sterile insect release programme to eradicate the codling moth, Cydia pomonella (L.) (Lepidoptera: Olethreutidae), in British Columbia, Canada. Management of insect pests: Nuclear and related molecular and genetic techniques.

54. Bloem S, Carpenter J, McCluskey A, Fugger R, Arthur S, et al. (2007) Suppression of the codling moth Cydia pomonella in British Columbia, Canada using an areawide integrated approach with an SIT component. Area-Wide Control of Insect Pests 591-601.

55. Carpenter JE, Blomefield T, Vreysen MJB (2012) A flight cylinder bioassay as a simple, effective quality control test for Cydia pomonella. Journal of Applied Entomology 136(9): 711-720.

56. Varela L, Johnson M, Strand D, Wilen C, Pickel C (2008) Light brown apple moth's arrival in California worries commodity groups. California Agriculture 62(2): 57-61.

57. Kean JM, Maxwell Suckling D, Stringer LD, Woods B (2011) Modeling the sterile insect technique for suppression of light brown apple moth (Lepidoptera: Tortricidae). Journal of economic entomology, 104(5): 1462-1475.

58. Chouinard G, Firlej A, Cormier D (2016) Going beyond sprays and killing agents: Exclusion, sterilization and disruption for insect pest control in pome and stone fruit orchards. Scientia Horticulturae 208: 13-27.

59. Simmons GS, Suckling DM, Carpenter JE, Addison MF, Dyck VA, et al. (2010) Improved quality management to enhance the efficacy of the sterile insect technique for lepidopteran pests. Journal of Applied Entomology 134(3): 261-273.

60. Vreysen MJB, Carpenter JE, Marec F (2010) Improvement of the sterile insect technique for codling moth Cydia pomonella (Linnaeus) 


\section{International Journal of Zoology and Animal Biology}

(Lepidoptera Tortricidae) to facilitate expansion of field application. Journal of Applied Entomology 134(3): 165-181.

61. Horner RM, Walker JTS, Rogers DJ, Lo PL, Suckling DM (2016) Use of the sterile insect technique in New Zealand: benefits and constraints. NZ Plant Prot 68: 296-304.

62. Calderón JS, Céspedes CL, Rosas R, Gómez-Garibay F, Salazar JR, et al. (2001) Acetyl cholinesterase and Insect Growth Inhibitory Activities of Gutierrezia microcephala on Fall Army worm Spodoptera frugiperda J. E. Smith. Z Naturforsch C 56(5-6): 382394.

63. Céspedes C, Alarcón J, Aranda E, Becerra J, Silva MZ (2001a) Insect Growth Regulator and Insecticidal Activity of Dihydro- $\beta$-agarofurans from Maytenus spp. (Celastraceae). Naturforsch C 569(7-8): 603-613.

64. Céspedes CL, Martinez-Vázquez M, Calderón JS, Salazar JR, Aranda EZ (2001b) Insect Growth Regulatory Activity of some extracts and compounds from Parthenium argentatum on Fall Armyworm (Spodoptera frugiperda). Naturforsch C 56(1-2): 95105.

65. Mordue AJ, Blackwel A (1993) Azadirachtin: an update. Journal of insect physiology 39(11): 903-924.

66. Richter K, Koolman J (1991) Antiecdysteroid effects of brassinosteroids in insects. ACS Symposium seriesAmerican Chemical Society.

67. Dinan L, Whiting P, Girault JP, Lafont R, Dhadialla TS et al. (1997) Cucurbitacins are insect steroid hormone antagonists acting at the ecdysteroid receptor. Biochem J 327(3): 643-650.

68. Altstein M, Aharonson N, Menn JJ (1993) Overview: New targets for insect management in crop protection. Archives of insect biochemistry and physiology 22(1-2): 5-12.

69. Staal GB (1977) Insect control with insect growth regulators based on insect hormones. Pontif Acad Sci Scr Varia 41: 353-83.

70. Williams CM (1967) Third-generation pesticides. Sci Am 217(1): 13-17.
71. Gade G (1997) The explosion of structural information on insect neuropeptides. Fortschritte der Chemie organischer Naturstoffe: 1-128.

72. Jarvis TD, Earley FGP, Rees HH (1994) Inhibition of the ecdysteroid biosynthetic pathway in ovarian follicle cells of Locusta migratoria. Pesticide Biochemistry and Physiology 48(2): 153-162.

73. Lorenz J, Lenz M, Hoffmann KH (1995) Effects of pharmacological agents on ecdysteroid synthesis in vitro in ovaries and abdominal integument from female adult crickets, Gryllus bimaculatus de Geer (Ensifera, Gryllidae). Zeitschrift für Naturforschung C 50(3-4): 286-293.

74. Wing KD, Aller HE (1990) Ecdysteroid agonists as novel insect growth regulators. Amsterdam, The Netherlands pp: 251-257.

75. Seth RK, Kaur JJ, Rao DK, Reynolds SE (2004) Effects of larval exposure to sublethal concentrations of the ecdysteroid agonists RH-5849 and tebufenozide (RH5992) on male reproductive physiology in Spodoptera litura. J Insect Physiol 50(6): 505-517.

76. Dhadialla TS, Carlson GR, Le DP (1998) New insecticides with ecdysteroidal and juvenile hormone activity. Annu Rev Entomol 43(1): 545-569.

77. Couillaud F (1995) Endocrine-based opportunities for insect control. Recent Advances in Insect Endocrine Research: 117-153.

78. Debernard S, Rossignol F, Couillaud F (1994) The HMG-CoA reductase inhibitor fluvastatin inhibits insect juvenile hormone biosynthesis. Gen Comp Endocrinol 95(1): 92-98.

79. Moya P, Castillo M, Primo-Yúfera E, Couillaud F, Martínez-Máñez R (1997) Brevioxime: a new juvenile hormone biosynthesis inhibitor isolated from Penicillium brevicompactum. J Org Chem 62(24): 8544-8545.

80. Prestwich GD (1986) Fluorinated Sterols, hormones and pheromones: enzyme-targeted disruptants in insects. Pestic Sci 37: 430-440.

81. Masler EP, Kelly TJ, Menn JJ (1993) Insect neuropeptides: discovery and application in insect management. Arch Insect Biochem Physiol 22(1-2): 87-111. 
82. Friedländer $M$, Seth RK, Reynolds SE (2005) Eupyrene and apyrene sperm: dichotomous spermatogenesis in Lepidoptera. Advances in Insect Physiology 32: 206-308.

83. Happ GM (1992) Maturation of the male reproductive system and its endocrine regulation. Annu Rev Entomol 37(1): 303-320.

84. He Y, Tanaka T, Miyata T (1995) Eupyrene and apyrene sperm and their numerical fluctuations inside the female reproductive tract of the armyworm, Pseudaletia separata. Journal of Insect Physiology 41(8): 689-694.

85. Watanabe M, Hachisuka A (2005) Dynamics of eupyrene and apyrene sperm storage in ovipositing females of the swallowtail butterfly Papilio xuthus (Lepidoptera: Papilionidae). Entomological Science 8(1): 65-71.

86. Yan S, Li H, Zhang J, Zhu J, Zhang Q, et al. (2013) Sperm storage and sperm competition in the Helicoverpa armigera (Lepidoptera: Noctuidae). J Econ Entomol 106(2): 708-715.

87. Silberglied RE, Shepherd JG, Dickinson JL (1984) Eunuchs: the role of apyrene sperm in Lepidoptera. The American Naturalist 123(2): 255-265.

88. Osanai M, Aigaki T, Kasuga H, Mohri H (1987a) New horizons in sperm cell research. Japan Scientific Societies Press, Tokyo, Japan, pp: 185-195.
89. Osanai M, Kasuga H, Aigaki T (1987b) Physiological role of apyrene spermatozoa of Bombyx mori. Experientia 43(6): 593-596.

90. Osanai M, Kasuga H, Aigaki T (1991) Motility-related ultra structural changes in the flagella membrane of apyrene spermatozoa of the silkworm Bombyx mori induced by Arg-C Endopeptidase. Invertebrate Reproduction and Development 19: 193-202.

91. Sugumaran M (1996) New Directions in Invertebrate Immunology; Söderhäll $\mathrm{K}$, et al. (Eds) SOS Publications: Fair Haven pp: 355-374.

92. Khot LR, Sankaran S, Maja JM, Ehsani R, Schuster EW (2012) Application of nanomaterials in agricultural production and crop protection: A review. Crop Prot 35: 64-70.

93. Debnath N, Mitra S, Das S, Goswami A (2012) Synthesis of surface functionalized silica nanoparticles and their use as entomotoxic nanocides. Powder technology 221: 252-256.

94. Chandrashekharaiah M, Kandakoor SB, Gowda GB, Kammar V, Chakravarthy AK (2015) Nanomaterials: A review of their action and application in pest management and evaluation of DNA-tagged particles. New Horizons in Insect Science towards Sustainable Pest Management pp: 113-126. 